\title{
MİKROBİYEL KSİLİTOL ÜRETİMİNDE HEMİSELÜLOZİK HIDROLIZATLARIN KULLANIMI
}

\author{
Kübra Eryaşar Örer, Seda Karasu Yalçın* \\ Abant İzzet Baysal Üniversitesi, Mühendislik Mimarlık Fakültesi, Gıda Mühendisliği Bölümü, Bolu, Türkiye \\ Geliş / Received: 10.10.2017; Kabul / Accepted: 02.12.2017; Online bask1 / Published online: 12.01.2018
}

Eryaşar Örer, K., Karasu Yalçın, S. (2018). Mikrobiyel ksilitol üretiminde hemiselülozik hidrolizatların kullanımı. GIDA (2018) 43 (1): 151-162 doi: 10.15237/gida.342722

\section{ÖZ}

Ksilitol, sakkaroza benzer tatlılık derecesi, düşük kalori ve glisemik indeks değerlerinin yanısıra antikariyojenik özelliği sayesinde gıda endüstrisinde kullanılan şeker alkolleri arasında yer almaktadır. Ksilitol üretimi, günümüzde oldukça yüksek maliyetler gerektiren kimyasal proseslerle sağlanmaktadır. Diğer taraftan, üretim maliyetlerini azaltma potansiyeli değerlendirildiğinde, son yıllarda yapılan çalışmalar mikrobiyel ksilitol üretimi üzerine odaklanmıştır. Mikrobiyel ksilitol üretimi çalş̧malarında yaygın olarak mayalar kullanılmaktadır. Çalışmalarda fermantasyon ortamı olarak, çeşitli lignoselülozik materyallerden hazırlanan ve ksilitol üretimi için gerekli substrat olan ksilozu içeren hemiselülozik hidrolizatlar kullanılmaktadır. Bu derleme, ksilitol ve fermantasyon yolu ile üretimi, ksilitol üretiminde doğal fermantasyon ortamı olarak kullanılan hemiselülozik hidrolizatların hazırlığı ve bu konuda son yıllardaki gelişmeleri içermektedir.

Anahtar kelimeler: Ksilitol, lignoselülozik materyal, hemiselülozik hidrolizat, fermantasyon

\section{UTILIZATION OF HEMICELLULOSIC HYDROLYSATES FOR MICROBIAL XYLITOL PRODUCTION}

\begin{abstract}
Xylitol is one of the sugar alcohols used in food and pharmaceuticals industries, with relative sweetness equivalent to sucrose, less calorie and glycemic index values, and also its anticariogenic properties. Today, it is industrially produced by chemical processes demanding considerable high costs. On the other hand, when its potential for reducing the costs is evaluated, studies in recent years are focused on microbial xylitol production. Yeasts are widely used in microbial xylitol production studies. In those studies, hemicellulosic hydrolysates prepared from various lignocellulosic materials and containing xylose necessary as substrate for the xylitol production are utilized as fermentation media. This review was focused on xylitol and its production by fermentation, preparation of hemicellulosic hyrolysates used as natural fermentation media in xylitol production and recent developments in this subject.
\end{abstract}

Keywords: Xylitol, lignocellulosic material, hemicellulosic hydrolysates, fermentation

\footnotetext{
*Yazışmalardan sorumlu yazar/ Corresponding author:

$\triangle$ yalcin_s@ibu.edu.tr

(f) (+90) $3742541000 / 4833$

且 (+90) 3742534558
} 


\section{GİRIŞ}

Ksilitol, sahip olduğu çeşitli olumlu özellikleri nedeniyle dünya çapında yoğun olarak talep gören bir şeker alkolüdür. Ülkemize ithalat yolu ile sağlanan ksilitol; endüstriyel olarak kimyasal yöntemlerin kullanıldığ1 proseslerle üretilmektedir. Ancak, kimyasal yöntemlerin gerektirdiği yüksek sıcaklık ve basınç değerlerinin sağlanması için yapılan enerji sarfiyatı ve üretimde hammadde olarak kullanilan saf ksilozun pahalı olması, ksilitol üretiminin oldukça maliyetli bir proses haline gelmesine yol açmaktadir. Bu nedenle, doğada bol miktarda bulunan ve ucuz substrat kaynakları olan çeşitli lignoselülozik materyallerden hazırlanan ve ksilitol üretimi için gerekli substrat olan ksiloz açısından zengin hemiselülozik hidrolizatların mikrobiyel ksilitol üretimlerinde doğal fermantasyon ortamı olarak kullanılması ile ilgili çalışmaların son yıllarda arttığ görülmektedir (Camargo vd., 2015). Ksilitol üretiminde mikroorganizmalar kullanıldığında çok daha düşük sıcaklıklarda çalışılma ve hemiselülozik hidrolizatlardaki ksilozun saflaştırılmadan substrat olarak kullanilma olanakları, üretim maliyetlerinin önemli ölçüde azalmasına katkı sağlamaktadır. Genel olarak, mayaların ksilitol üretimi potansiyellerinin daha yüksek olduğu belirtilen çalışmalarda, lignoselülozik materyal olarak oldukça fazla çeşitlilikteki gıda, tarım ve ormancilık endüstrisi artıklarının değerlendirildiği görülmektedir (Albuquerque vd., 2014).

Mikrobiyel ksilitol üretimi çalışmaları için fermantasyon ortamı hazırllğı sürecinde, ilk olarak lignoselülozik materyaller çoğunlukla seyreltik sülfürik asit çözeltisinin kullanıldığı bir hidrolizasyon işlemine maruz bırakılmaktadır. Elde edilen hemiselülozik hidrolizatların, hammadde kaynağ1 ve işlem parametrelerine göre farklılık gösteren miktarlarda ksiloz içerdikleri bilinmektedir (Ur Rehman vd., 2015). Ancak, hazırlık sürecini nispeten zorlaştıran aşama, hidrolizatlarda ksilozun yanısıra mikroorganizma gelişimini olumsuz yönde etkileyen furfural, hidroksimetil furfural (HMF), fenolik bileşikler ve asetik asit gibi birtakım inhibitör bileşenlerin ortaya çıkmasıdır. Dolayısıyla, elde edilen hemiselülozik hidrolizatların fermantasyon ortamı olarak kullanılabilmesi için, öncelikle içerdiği inhibitör bileşenlerinden etkin bir şekilde arındırılması gerekmektedir. Bu amaçla, vakum evaporasyonu, iyon değiştirici reçine kullanımı, aşırı alkalileştirme veya $\mathrm{pH}$ ayarlama ve aktif kömür ile muamele işlemlerinden siklikla yararlanıldığ1 görülmektedir (Albuquerque vd., 2015).

\section{KSILLITTOL VE BIYYOTEKNOLOJIKK YOLLA ÜRETİMİ}

Ksilitol, ağırlıklı olarak gida ve eczacılık endüstrilerinde alternatif bir tatlandırıcı olarak kullanılan beş karbonlu bir şeker alkolüdür (Ur Rehman vd., 2015). Emülsifiye edici, nem tutucu, kıvam arttırıc1 ve tatlandırıc olma fonksiyonları sayesinde, g1dalarda E967 kodlu katk1 maddesi olarak kullanılan ksilitol, Amerikan Gıda ve İlaç Dairesi (FDA) tarafindan 'genel olarak güvenilir kabul edilen (GRAS)' bileşenler sınıfına dahil edilmiştir (Grembecka, 2015; Zada vd., 2017). Sakkaroz ile aynı tatllık derecesine sahip olmakla birlikte kalori değeri yaklaşı üçte bir oranında olan ksilitol, düşük kalorili ürünlerin üretiminde kullanilabilme potansiyeline sahiptir (Ur Rehman vd., 2015). Sağlıklı beslenmeye olan ilginin artması ile beraber toplumlar şekersiz ve düşük kalorili gıda ürünlerini tüketmeye yönelmiş, bu durum ksilitol talebinin artmasına yol açmıştır. Dünya genelinde, 2013 yllinda yaklaş1k 160 bin ton olduğu belirlenen ksilitol tüketiminin önümüzdeki yıllarda 240 bin tonlara; piyasadaki ekonomik değerinin ise 670 milyon dolardan 1 milyar dolara yükseleceği tahmin edilmektedir (Rao vd., 2016; Dasgupta vd., 2017). Çözünme sıcaklığının negatif olması sayesinde ağza alındığında ferahlık hissi sağladığından, ksilitol genel olarak sakız, şekerleme ve çikolata gibi ürünlerin üretiminde kullanılmaktadır (Albuquerque vd., 2014; Mohamad vd., 2015). Üretilen ksilitolün oldukça büyük bir çoğunluğunun sakız endüstrisi tarafindan kullanıldığı rapor edilmiştir. Glisemik indeks değeri sakkaroza göre oldukça düşük olan ksilitol, insülinden bağımsız olarak metabolize edildiğinden, diyabet hastalarına yönelik ürünlerde kullanabilen alternatif bir tatlandırıcıdır (Jain ve Mulay, 2014; Grembecka, 2015). Ksilitolün antikariyojenik özellik gösterdiği ve bu nedenle, diş macunu, ağız çalkalama suyu gibi kişisel bakım 
ürünlerinde kullanıldığı bilinmektedir (Rafiqul ve Mimi Sakinah, 2013; Ur Rehman vd., 2015).

Ticari olarak ilk büyük ölçekli ksilitol üretimine, 1975 yllında Finlandiya'da başlandığı belirtilmektedir. Ksilitol üretimi kimyasal olarak; ticari ksilozun veya çeşitli lignoselülozik materyallerden elde edilen ve ardından saflaştırilan ksilozun, oldukça yüksek basınç (31-40 atm) ve sıcaklık $\left(100-130^{\circ} \mathrm{C}\right)$ koşulları altında Raney nikel katalizörü eşliğinde ksilitole indirgenmesi ile gerçekleştirilmektedir (Albuquerque vd., 2014; Dasgupta vd., 2017). Kimyasal yolla ksilitol üretiminde, hammadde kaynağ1 olarak lignoselülozik materyallerden elde edilen ksiloz içeriği bakımından zengin hidrolizatların kullanılabilmesine yönelik çeşitli çalışmalar yapılmaktadır. Ancak, hem yüksek basınç ve sıcaklık koşullarının sağlanması için gerekli donanım ve enerji maliyetlerinin fazla olması hem de saflaştırma işlemlerinin oldukça fazla maliyet gerektirmesinden dolayı, kimyasal yöntemlerin kullanıldığ 1 ksilitol üretiminin pahalı bir süreç olduğu bilinmektedir (Albuquerque vd., 2014; Dalli vd., 2017). Bununla beraber, ksilitol günümüzde halen kimyasal yöntemlerle üretilmektedir. Dünya genelindeki en büyük ksilitol üreticisi olan bir işletmenin, ksilitol üretiminde hammadde olarak, kağıt hamuru ve kağıt endüstrisi artıklarından elde ettikleri ksilozu kullandığ1 belirtilmektedir (Albuquerque vd., 2014).

Ksilitolün kimyasal yöntemlerle üretiminde karşılaşılan zorluklar, son yıllarda araştırmacıları üretim için alternatif proses arayışlarına yöneltmiş ve ksilitolün fermantasyon yolu ile (mikrobiyel) ve enzimatik olarak üretilebileceği iki farklı biyoteknolojik yaklaşım geliştirilmiştir. Ksilitol üretiminin yaygin olarak, lignoselülozik materyalin asit veya enzim aracillğı ile hidrolize edilmesi ve ksiloz kaynağı olarak elde edilen hemiselülozik hidrolizatların içerdiği inhibitör bileşenlerden arındırılması aşamalarından sonra fermantasyona tabi tutulmaları ile gerçekleştirildiği bilinmektedir (Rafiqul ve Mimi Sakinah, 2013). Kimyasal yöntemler ile kıyaslandığında, hidrolizattaki ksilozun saflaştırılmadan ksilitol üretiminde kullanılabilmesi ve üretimde kullanılan düşük sicaklikların fazla enerji gerektirmemesi nedenleri ile üretim maliyetlerinin önemli ölçüde azaltılabildiği belirtilmektedir (Mohamad vd., 2015). Ksilitol üreticisi oldukları bilinen mikroorganizmalar arasinda başlica Scheffersomyces (Pichia), Debaryomyces ve Candida cinslerine ait maya suşlarının olduğu bildirilmekte ve özellikle Candida cinsi mayaların daha yüksek verimlerde ksilitol ürettikleri rapor edilmektedir (Cheng vd., 2010). Gerçekleştirilen bazı çalışmalarda, Candida tropicalis türüne ait mutant veya rekombinant suşlar ile (Jeon vd., 2011; Guo vd., 2013), rekombinant Saccharomyces cerevisiae (Li vd., 2013) ve Debaryomyces hansenii (Pal vd., 2013) suşlarının ksilitol üretimlerinde kullanıldıklar1 rapor edilmiştir. Ayrıca, rekombinant Corynebacterium glutamicum ve Escherichia coli bakteri türlerinin ksilitol üretiminde kullanıldığ 1 bilinmektedir (Kim vd., 2010; Su vd., 2015). Yapılan bir çalışmada, Candida cinsi 28 adet izolat arasinda, C. tropicalis MVP 16 suşunun en yüksek verimde ksilitol ürettiği belirtilmiştir (Lourenço vd., 2014). Guamán Burneo vd. (2015) tarafindan gerçekleştirilen bir çalışmada ise, C. tropicalis türüne ait bir suşun yanısıra, Cyberlindnera galapagoensis suşu kullanılarak en yüksek değerlerde ksilitol üretilebildiği bildirilmiştir. Bir diğer çalışmada, Cyberlindnera saturnus suşunun en yüksek derişimde ksilitol ürettiği rapor edilmiştir (Kamat vd., 2013).

Ksilitol, mikroorganizmaların ksilozu fermente etmeleri sırasında açığa çıan bir ara üründür. Mayaların ksilozdan ksilitol üretim metabolizmasının, indirgenme ve yükseltgenme basamaklarını içeren bir dizi reaksiyondan oluştuğu görülmektedir. Ksiloz, NADPH veya NADH bağıml ksiloz redüktaz (KR) enzimi varllğında indirgenerek ksilitole dönüşmekte, ardından elde edilen ksilitol hücre dışına salınmakta veya ortamda $\mathrm{NADP}^{+}$veya NAD ${ }^{+}$bağımlı ksilitol dehidrogenaz $(\mathrm{KDH})$ enziminin olması durumunda ksiluloza okside olmaktadır. Ksilozdan fermantasyon yolu ile ksilitol üretimini düzenleyen enzimler olan KR ve $\mathrm{KDH}$ enzimleri arasındaki oranın, KR yönünde fazla olması, hücre içerisinde ksilitol birikimini sağlamaktadır (Winkelhausen ve Kuzmanova, 1998; Mohamad vd., 2016). 


\section{LİGNOSELÜLOZİK KAYNAKLARIN KSIILİTOL ÜRETİMİ AMACIYLA DEĞERLENDİRİLMESİ}

Doğada bol miktarda bulunan, gida, tarım ve ormancılık endüstrisi artığ1 olabilen çeşitli lignoselülozik materyallerin ksilitol üretimi amac1 ile değerlendirilebilecek ucuz birer substrat kaynağ1 olduğu bilinmektedir (Jönsson ve Martín, 2016). Lignoselülozik materyaller selüloz, hemiselüloz ve lignin birimlerinden oluşmaktadır. Selülozik kısım, birbirlerine $\beta-1,4$ glikozidik bağları ile bağlanmış $\mathrm{D}$-glukoz birimlerinden meydana gelen, yarı kristal (düzenli) yapı taşıyan bir homopolisakkarittir. Lignoselülozik materyallerin yaklaşık olarak \%34-50'sinin selülozdan oluştuğu belirtilmektedir. Lignoselülozik materyal-deki hemiselülozik kısım ise, genel olarak pentoz ve heksoz şekerlerden, üronik asit ve asetil yan gruplarından oluşan heteropolisakkarit bir yapıdadır. Mikrobiyel ksilitol üretimi için gerekli substrat olan ksilozun pentoz bir şeker olduğu ve hemiselülozik kısımda yer aldığ 1 bilinmektedir. Hemiselüloz, sahip olduğu düzensiz yapısı ile doğrusal bir polimer olan selülozdan ayrılmaktadır. Lignoselülozik materyalin yaklaşık \%19-35'ini oluşturan hemiselülozun kimyasal yapısı ve bileşimi, bulunduğu bitki ve ağaç türlerine göre farkllılı gösterebilmektedir. Lignoselülozik materyallerdeki bir diğer önemli kısım, fenolik maddelerin ester bağları ile birbirlerine bağlandıkları aromatik polimer bir madde olan lignindir (Rafiqul ve Mimi Sakinah, 2013).

Literatürdeki çalışmalar incelendiğinde; mısır koçanı (Li vd., 2012; Misra vd., 2013; Wang vd., 2013a), şeker pancar1 posası (Silva vd., 2015, Castañón Rodríguez vd., 2015), şeker pancarı sap1 (Hernández Pérez vd., 2016), pirinç sap1 (Deng vd., 2007), pirinç kavuzu (Rambo vd., 2013), pamuk tohumu kabuğu (Wang vd., 2013b), sebze artıklar1 (Zhang vd., 2012b), kaju fistığ1 posas1 (Rocha vd., 2014; Albuquerque vd., 2015), üzüm posas1 (Salgado vd., 2012), bira ve şarap tortusu (Pérez Bibbins vd., 2015), kahve meyvesi kabuğu (Arrizon vd., 2012), muz kabuğu, maş fasulyesi, yer fistığ1 ve yulaf kabukları (Ur Rehman vd., 2015), asma budama artıklar1 (Rivas vd., 2007) ve kestane kabuğu (Eryaşar ve Karasu Yalçın, 2016) gibi farklı gida ve tarım endüstrisi artıklarından elde edilen, ksiloz içerikleri yüksek hemiselülozik hidrolizatların ksilitol üretiminde substrat olarak kullanıldığ1 görülmektedir. Ayrıca, zeytin ağac1 budama artıklar1 (Mateo vd., 2013) ile ökaliptus ağac1 (Villarreal vd., 2006), huş ağac1 (Miura vd., 2015) ve bambu ağac1 (Miura vd., 2013) kabuklarını kapsayan ormancilı endüstrisi artıklarının hidrolizat hazırlığında hammadde olarak değerlendirildiği bilinmektedir.

Mikrobiyel ksilitol üretiminde fermantasyon ortamı olarak kullanılan hidrolizatların hazırlı̆̆ında hedeflenen, ksiloz içeriklerinin mümkün olduğu kadar yüksek, mikroorganizma gelişimi üzerine olumsuz etki gösterebilen çeşitli inhibitör bileşenlerin ise en düşük seviyelerde olduğu hemiselülozik hidrolizatların elde edilebilmesidir (Rafiqul ve Mimi Sakinah, 2013). Ancak, çok yüksek derişimlerde ksiloz içeren hemiselülozik hidrolizatların ksilitol üretimde kullanıldığ1 bazı çalışmalarda, mikroorganizmaların ksiloz fermantasyonu metabolizmalarının olumsuz yönde etkilendiği bildirilmektedir ve bu durumun ksilozun yanısıra, hemiselülozik hidrolizatlarda bulunan inhibitör bileşenlerin derişimlerinin de daha yüksek olması ile açıklanmaktadır (Li vd., 2012). Ayrica, üretimde kullanılan farklı suşların ksilitol üretimi kapasitelerinin de farklı olması ve hemiselülozik hidrolizatların kimyasal bileşimlerinin değişkenlik göstermesi nedenleri ile, ksiloz içeriği yüksek olan fermantasyon ortamlarında her zaman en yüksek derişimlerde ksilitol üretimi yapılamadığı bildirilmektedir. Tüm bu nedenlerle, mikrobiyel ksilitol üretimi çalışmaları için, lignoselülozik materyallerden hemiselülozik hidrolizat hazırllğı aşamalarının uygun yöntemler kullanılarak optimum koşullar altında gerçekleştirilmesi ve hazırlanan fermantasyon ortamlarında ksilitol üretme kapasitesi yüksek suşların seçilmesi oldukça büyük bir önem taşımaktadır (Mussatto ve Roberto, 2008).

Hemiselülozik hidrolizat hazırlı̆̆ının başlangıç noktası olarak, lignoselülozik materyallere hidrolizasyon işlemi uygulanarak, bu materyallerdeki hemiselülozik yapının açığa çıkarılması ve bu sayede ksiloz içeren bir hidrolizatın elde edilmesi 
sağlanmaktadır. Yapılan bazı çalışmalarda, hidrolizasyon öncesinde lignoselülozik materyallere birtakım ön işlemlerin uygulanarak, hidrolizasyon etkinliğinin arttırılmaya çalışıldığı belirtilmektedir. Bazı çalışmalarda ise, lignoselülozik materyaller doğrudan, belirlenen uygun hidrolizasyon yöntem ve parametreleri kullanılarak hidrolize edilmektedir. Lignoselülozik materyallere, genel olarak fizikokimyasal veya kimyasal yöntemlerin kullanıldığı ön işlemler uygulandiğında, bu materyallerin yapisal bütünlüklerinin bozulduğu, ligninin ortamdan uzaklaştırıldığı, hemiselülozik yapının parçalanarak açığa çıkmasının kolaylaştırıldığı ve dolayısıyla ksiloz derişimlerinin arttırılabildiği bildirilmektedir (Ur Rehman vd., 2015; Chen vd., 2017). Kimyasal yöntemlerden yararlanılan ön işlemlerde çeşitli alkali, amonyak ve asit çözeltilerinin, organik çözücülerin veya oksitleyici ajanların kullanıldığ1 rapor edilmektedir (Rao vd., 2016). Örneğin, ksilitol üretiminde fermantasyon ortam1 olarak pirinç sapı hidrolizatının kullanıldığı bir çalışmada, materyalin amonyak çözeltisi ile muamele edilmesinin hidrolizatın ksiloz içeriğini bir miktar arttırmasının yanısıra inhibitör bileşenlerin de ortamdan uzaklaştırılmasına katk1 sağladığ1 ve bu sayede hazırlanan hidrolizatın maya suşu tarafindan fermente edilme kapasitesinin arttı̆̆1 belirlenmiştir (Deng vd., 2007). Rocha vd., (2014) tarafindan gerçekleştirilen bir başka çalışmada ise, seyreltik asit çözeltisine belirli oranda ilave edilen kaju fistı̆̆ posasının $121^{\circ} \mathrm{C}$ 'de 15 dakika süresince bekletilmesi ile daha fazla miktarda hemiselülozik yapının açığa çıktığı bildirilmiştir. Ayrıca, hidrojen peroksit çözeltisinin, lignini yaklaşık \%50 oranında uzaklaştırdığı ve hemiselülozun büyük bir miktarını parçaladığı; ozonun ise hemiselülozik yapıya fazla etki etmediği, ancak lignin miktarını azalttığı rapor edilmiştir. Lignoselülozik materyallere uygulanan ön işlemlerde, mikrodalga uygulamas1, ekstrüderlerde muamele ve yüksek basınçlı buhar uygulamaları gibi fizikokimyasal yöntemlerin kullanıldığ1 bilinmekte ve genel olarak bu yöntemlerin materyallerdeki hemiselülozik yapının parçalanarak açığa çıkmasına katkı sağladıkları bildirilmektedir (Rao vd., 2016).
Literatürdeki çalışmaların büyük bir çoğunluğunda, hidrolizasyon işlemlerinde seyreltik sülfürik asit çözeltisinden yararlanılmaktadır. Seyreltik asit hidrolizasyonunun, genel olarak düşük derişimlerde asit çözeltileri kullanılarak, yüksek sıcaklık ve basınç koşullarında gerçekleştirildiği ve bu sayede, substrat kaynağı olarak hemiselülozik yapıdaki ksilozun açığa çıkarılmasının sağlandığı belirtilmektedir. Hidrolizat hazırllğında hammadde olarak değerlendirilen lignoselülozik materyalin cinsine, kullanılan asite ve derişimine, uygulanan sıcaklık ve süreye, ayrıca katı materyal ve çözelti oranına bağlı olarak, elde edilen hidrolizatlardaki ksiloz derişimlerinin değiştiği bildirilmektedir (Rafiqul ve Mimi Sakinah, 2013). Misır koçanı hidrolizatı hazırlamak üzere materyalin 1:10 (w/v) oranında \%1'lik sülfürik asit çözeltisi ile karıştırıldığ1 ve $121^{\circ} \mathrm{C}$ 'de 60 dakika süresince hidrolize edildiği durumda $16.36 \mathrm{~g} / \mathrm{L}$ ksilozun açığa çıktığı, hidrolizasyon işlemi belirlenen optimum koşullarda (\%1'lik sülfürik asit çözeltisi, $1: 8,121^{\circ} \mathrm{C}, 30$ dakika) gerçekleştirildiğinde ise $21.98 \mathrm{~g} / \mathrm{L}$ ksiloz elde edildiği rapor edilmiştir (Misra vd., 2013). Zeytin ağacı budama artıkları, $\% 2$ 'lik sülfürik asit çözeltisi kullanılarak ve $120^{\circ} \mathrm{C}$ 'de 90 dakika süresince hidrolize edildiğinde, hidrolizasyon işlemi için optimum koşulların sağlandığı ve bu durumda en yüksek $17.97 \mathrm{~g} / \mathrm{L}$ ksiloz elde edildiği rapor edilmiştir (Mateo vd., 2014).

\section{HEMİSELÜLOZİK HİDROLİZATLARIN İNHİBİTÖRLERDEN ARINDIRILMASI ICCIIN UYGULANAN İŞLEMLER}

Lignoselülozik materyallere uygulanan seyreltik asit hidrolizasyonu sırasında açığa çıkan, hidrolizatlardaki derişimleri kullanılan lignoselülozik materyale ve hidrolizasyon yöntemine bağlı olarak değişebilen furfural, HMF, asetik asit ve fenolik maddeler gibi çeşitli inhibitör bileşenlerin, hemiselülozik hidrolizatların fermantasyon ortamı olarak kullanıldığı mikrobiyel ksilitol üretimi çalışmalarında karşılaşılan en yaygin problem olduğu bilinmektedir (Gupta vd., 2017). Rafiqul vd., (2015) tarafindan gerçekleştirilen bir çalışmada, hemiselülozik hidrolizatlardaki çeşitli inhibitörlerin C. tropicalis IFO 0618 suşunda bulunan ve ksilitol üretiminde kritik bir önemi olan ksiloz redüktaz (KR) enzimini inhibe ettiği 
rapor edilmiştir. Lignoselülozik materyallerin asit ile muamele edildiği durumlarda, hemiselülozun parçalanması ile elde edilen pentoz şekerler ve üronik asitten furfural (2-furaldehit) ve heksoz şekerlerden HMF açığa çıkmaktadır (Rao vd., 2016). Genel olarak, kimyasal hidrolizle selülozun çok az miktarda parçalanması nedeni ile hemiselülozik yapıda heksoz şekerler daha düşük miktarlarda bulunduğundan, furfural ile kıyaslandığında, elde edilen hidrolizatlarda HMF oluşumunun daha az olduğu bilinmektedir ( $\mathrm{Ur}$ Rehman vd., 2015). Daha yüksek sicaklık değerleri ile yüksek derişimdeki asitlerin kullanıldığı ve daha uzun süreli hidrolizasyon işlemlerinde, HMF ve furfural bileșenlerinden levulinik ve formik asitlerin oluştuğu bilinmektedir. Hemiselülozdaki asetil gruplarının yıkımı sonucu oluşan asetik asit ise hidrolizatlarda bulunabilen bir diğer inhibitör bileşendir. Ayrıca, lignin molekülünün yıkımı ile yaygin olarak, 4-hidroksibenzaldehit, vanilin, siringaldehit, $p$-kumarik asit ve ferulik asit gibi fenolik maddeler meydana gelmektedir (Jönsson ve Martín, 2016).

Hemiselülozik hidrolizatlardaki inhibitör bileşenlerin, fermantasyon ortamının pH'sı ve çözünmüş oksijen derişimi, ortamda bulunan diğer inhibitörler ve kullanılan mikroorganizmaların inhibitörlere karşı gösterdikleri direnç gibi parametrelere bağlı olarak, mikroorganizma gelişimini farklı seviyelerde etkiledikleri belirtilmektedir (Ur Rehman vd., 2015, Rao vd., 2016). Çeşitli çalışmalarda, hidrolizasyon sırasında açığa çıkan furfural ve HMF bileşenlerinin hücre bölünmesini engellediği ve Scheffersomyces stipitis ve $S$. cerevisiae gibi bazı mikroorganizmaların gelişimini inhibe eden başlıca bileşen olduğu bilinmektedir (Chandel vd., 2013). Fermantasyon ortamında $0.5-2 \mathrm{~g} / \mathrm{L}$ aralığındaki derişimlerde furfural bulunduğu durumlarda mikroorganizma gelişiminin \%25-99 oranında azaldığ1 bildirilmektedir (Ur Rehman vd., 2015). Diğer yandan, bazı mikroorganizmaların aerobik koşullar altında, furfural bileşenini okside ederek daha az toksik etki gösteren furoik asite dönüştürebildikleri rapor edilmiştir (Wannawilai vd., 2017). Fermantasyon sürecinde inhibitör etki gösteren bileşenlerden asetik asit ise, düşük $\mathrm{pH}$ değerlerinde yağda çözünerek plazma membra- nına difüze olmakta, hücre içerisindeki nötral pH'larda ise iyonlarına ayrışarak sitoplazmada birikmektedir. Bu sırada açığa çıkan protonların hücre pH'sını düşürerek mikroorganizma aktivitelerini inhibe ettiği ve mikroorganizmaların ölümüne neden olduğu belirtilmektedir. Fermantasyon ortaminda $1 \mathrm{~g} / \mathrm{L}$ 'ye kadar bulunan asetik asitin ksilitol üretimini teşvik ettiği, $3 \mathrm{~g} / \mathrm{L}$ ve üzerindeki derişimlerin ise fermantasyonu olumsuz etkilediği bildirilmiştir. (Chandel vd., 2013). Ayrıca, lignoselülozik materyallerdeki ligninin parçalanması sonucu oluşan başlica inhibitörlerden olan fenolik bileşikler, hücre membranının seçici geçirgenlik özelliğini kaybetmesine yol açarak mikroorganizma gelişimi ve ksilitol üretimini etkilemektedir. Candida guilliermondii suşu kullanılarak gerçekleştirilen bir çalışmada, fermantasyon ortamının oldukça düşük miktarlarda $(0.1 \mathrm{~g} / \mathrm{L})$ fenolik madde içermesi durumunda bile, ksilitol üretiminin olumsuz etkilendiği bildirilmiştir (Chandel vd., 2013). Ksilitol üretiminde Candida athensensis suşunun kullanıldığı bir başka çalışmada ise; 1 $\mathrm{g} / \mathrm{L}$ 'den daha düşük derişimde fenolik madde içeren fermantasyon ortamlarında gerçekleştirilen üretimlerde olumsuz sonuçların alınmadığı belirtilmiştir (Zhang vd., 2012a).

Hemiselülozik hidrolizatlardaki inhibitör bileşenlerin ksilitol üretimine etkisinin mümkün olduğunca düşük seviyelerde tutulması için; hidrolizasyonun daha ılımlı koşullarda gerçekleştirilmesi, inhibitörlere karşı yüksek direnç gösterebilen mikroorganizmaların seçilmesi veya hidrolizatların içerdiği inhibitör bileşenlerden arındirılmasinın (detoksifikasyon) ardindan fermantasyon ortamı olarak değerlendirilmesi önerilmektedir (Ur Rehman vd., 2015). Yapilan bazı mikrobiyel ksilitol üretimi çalışmalarında ise; fermantasyon ortamı olarak inhibitör bileşenlerden arındırılmamış hemiselülozik hidrolizatlardan yararlanıldığı belirtilmiştir (Ping vd., 2013). Ancak, oldukça yaygın bir şekilde, çeşitli fiziksel, kimyasal veya biyolojik yöntemler ile detoksifiye edilen hidrolizatların fermantasyon ortamı olarak kullanıldığı bilinmektedir. Hemiselülozik hidrolizatlara uygulanacak detoksifikasyon yöntemi, fermantasyonda kullanılan mikroorganizma türüne ve hidrolizatın kimyasal bileşimine bağlı olarak 
değişkenlik gösterebildiğinden, her çalışma için uygun bir yöntem belirlenmelidir. Uygulanan işlemlerin ksilitol üretim maliyetini arttırdığ göz önüne alındığında, bu aşamada ucuz ve etkili yöntemlerin kullanılması oldukça büyük bir önem taşımaktadır (Ur Rehman vd., 2015, Vallejos vd.,
2016). Çizelge 1'de, çeşitli çalışmalarda kullanılan hemiselülozik kaynaklar, hidrolizasyon ve detoksifikasyon yöntemleri ile elde edilen hidrolizattaki ksiloz miktarları verilmiştir.

Çizelge 1. Hemiselülozik hidrolizatlar kullanılarak mikrobiyel ksilitol üretiminin gerçekleştirildiği çeşitli çalışmalara ait bilgiler

\begin{tabular}{|c|c|c|c|c|c|}
\hline Mikroorganizma & $\begin{array}{l}\text { Substrat } \\
\text { kaynağ1 }\end{array}$ & $\begin{array}{l}\text { Hidrolizasyon } \\
\text { yöntemi }\end{array}$ & $\begin{array}{l}\text { Detoksifikasyon } \\
\text { yöntemi }\end{array}$ & $\begin{array}{l}\text { Ksiloz } \\
\text { derişimi } \\
(\mathrm{g} / \mathrm{L})\end{array}$ & Kaynak \\
\hline C. guilliermondii & Kavak ağac1 & $\begin{array}{l}\text { Seyreltik } \mathrm{H}_{2} \mathrm{SO}_{4} \\
\left(\% 1.75,120^{\circ} \mathrm{C}, 2\right. \\
\text { sa) }\end{array}$ & $\begin{array}{l}\text { Vakum evaporasyonu } \\
\left(65^{\circ} \mathrm{C}\right) \text { ve organik } \\
\text { çözücü ekstraksiyonu } \\
\text { (toluen ile) }\end{array}$ & 102.4 & $\begin{array}{l}\text { Dalli vd. } \\
2017\end{array}$ \\
\hline C. magnoliae & Huş ağac1 & $\begin{array}{l}\text { Seyreltik } \mathrm{H}_{2} \mathrm{SO}_{4} \\
\left(\% 3,120^{\circ} \mathrm{C}, 1 \mathrm{sa},\right. \\
1: 4)\end{array}$ & $\begin{array}{l}\text { Aktif kömür ile } \\
\text { muamele }(15 \mathrm{~g} / \mathrm{L}, 160 \\
\left.\text { vuru/dak, } 30^{\circ} \mathrm{C}, 1 \mathrm{sa}\right) \\
\text { ve anyon değiştirici } \\
\text { reçine ile muamele } \\
(80 \mathrm{~g} / \mathrm{L})\end{array}$ & 37.6 & $\begin{array}{l}\text { Miura } \\
\text { vd., } 2015\end{array}$ \\
\hline C. tropicalis & $\begin{array}{l}\text { Şekerpancar1 } \\
\text { posas1 }\end{array}$ & $\begin{array}{l}\text { Seyreltik } \mathrm{H}_{2} \mathrm{SO}_{4} \\
(100 \quad \mathrm{mg} / \mathrm{g}, \\
121^{\circ} \mathrm{C}, 20 \mathrm{dak}, \\
1: 10)\end{array}$ & $\begin{array}{l}\text { pH ayarlama ve aktif } \\
\text { kömür ile muamele } \\
(\% 2.5 \mathrm{w} / \mathrm{v}, 200 \mathrm{rpm} \text {, } \\
\left.30^{\circ} \mathrm{C}, 1 \mathrm{sa}\right)\end{array}$ & 49.7 & $\begin{array}{l}\text { Guáman- } \\
\text { Burneo } \\
\text { vd., } 2015\end{array}$ \\
\hline C. magnoliae & Bambu ağac1 & $\begin{array}{l}\text { Seyreltik } \mathrm{H}_{2} \mathrm{SO}_{4} \\
\left(\% 3,121^{\circ} \mathrm{C}, 1 \mathrm{sa},\right. \\
1: 10)\end{array}$ & $\begin{array}{l}\text { Aktif kömür ile } \\
\text { muamele }(20 \mathrm{~g} / \mathrm{L}, 160 \\
\text { vuru/dak, } 30^{\circ} \mathrm{C}, 24 \\
\text { sa) }\end{array}$ & 19.4 & $\begin{array}{l}\text { Miura } \\
\text { vd., } 2013\end{array}$ \\
\hline C. tropicalis & Misır koçanı & $\begin{array}{l}\text { Seyreltik } \mathrm{H}_{2} \mathrm{SO}_{4} \\
\left(\% 1,121^{\circ} \mathrm{C}, 40\right. \\
\text { dak, 1:10) }\end{array}$ & $\begin{array}{l}\mathrm{pH} \text { ayarlama ve aktif } \\
\text { kömür ile muamele } \\
(1: 40 \mathrm{w} / \mathrm{v}, 200 \mathrm{rpm}, \\
\left.30^{\circ} \mathrm{C}, 1 \mathrm{sa}\right)\end{array}$ & $\begin{array}{l}31.25^{\mathrm{a}} \\
160^{\mathrm{b}}\end{array}$ & $\begin{array}{ll}\text { Li vd., } \\
2012\end{array}$ \\
\hline D. hansenii & Üzüm posas1 & $\begin{array}{l}\text { Seyreltik } \mathrm{H}_{2} \mathrm{SO}_{4} \\
\left(\% 3.3,130^{\circ} \mathrm{C}, 15\right. \\
\text { dak, 1:8) } \\
\end{array}$ & $\begin{array}{l}\text { Aktif kömür ile } \\
\text { muamele }(1: 10 \mathrm{w} / \mathrm{v}, \\
\text { oda sıcaklı̆gında, } 1 \mathrm{sa})\end{array}$ & $\begin{array}{l}7.8^{\mathrm{a}} \\
50.1^{\mathrm{b}}\end{array}$ & $\begin{array}{l}\text { Salgado } \\
\text { vd., } 2012\end{array}$ \\
\hline C. athensensis & $\begin{array}{l}\text { Sebze } \\
\text { artıklar1 }\end{array}$ & $\begin{array}{l}25^{\circ} \mathrm{C} \text { 'de suda } 1 \\
\text { gece ve etanol/ } \\
\text { seyreltik } \mathrm{H}_{2} \mathrm{SO}_{4} \\
\text { karışımında } \\
\text { bekletme }\left(65^{\circ} \mathrm{C} \text {, }\right. \\
4 \text { sa) }\end{array}$ & $\begin{array}{l}\mathrm{pH} \text { ayarlama ve aktif } \\
\text { kömür ile muamele } \\
(\% 2 \mathrm{w} / \mathrm{v}, 200 \mathrm{rpm}, \\
\left.30^{\circ} \mathrm{C}, 1 \mathrm{sa}\right)\end{array}$ & 123.42 & $\begin{array}{l}\text { Zhang } \\
\text { vd., } \\
\text { 2012b }\end{array}$ \\
\hline D. hansenii & $\begin{array}{l}\text { Asma } \\
\text { budama } \\
\text { artıklar1 }\end{array}$ & $\begin{array}{l}\text { Seyreltik } \mathrm{H}_{2} \mathrm{SO}_{4} \\
\left(30 \mathrm{~g} / \mathrm{kg}, 130^{\circ} \mathrm{C},\right. \\
15 \mathrm{dak}, 1: 8)\end{array}$ & $\begin{array}{l}\text { Aktif kömür ile } \\
\text { muamele }(20 \mathrm{~g} / \mathrm{g} \text {, oda } \\
\text { sicaklı̆̆ında, } 1 \mathrm{sa})\end{array}$ & $\begin{array}{l}14.6^{\mathrm{a}} \\
57.3^{\mathrm{b}}\end{array}$ & $\begin{array}{l}\text { Rivas vd., } \\
2007\end{array}$ \\
\hline
\end{tabular}


Hemiselülozik hidrolizatların inhibitörlerden arındırılmasında fiziksel yöntemlerden olan vakum evaporasyonu kullanıldığında asetik asit, furfural, HMF ve vanilin gibi uçucu inhibitör bileşenlerin oldukça büyük bir çoğunluğunun uzaklaştırılabildiği bildirilmiştir. Ancak, bu yöntemin uçucu olmayan inhibitörlerin derişimini arttırdığ1 ve hidrolizat hacmini önemli ölçüde azalttığı bilinmektedir. Aşırı alkalileştirme veya pH ayarlama, organik çözücü ekstraksiyonu, iyon değiştirici reçine kullanımı ve aktif kömür ile muamele uygulamalar1 ise detoksifikasyonda kullanılan kimyasal yöntemlerdendir. Hidrolizatların içerdiği fenolik madde, keton, furfural ve HMF inhitörlerinden arındırılması amaciyla, genel olarak kalsiyum hidroksit ile sülfürik asit çözeltilerinin bir arada kullanıldığı $\mathrm{pH}$ ayarlama yöntemi sıklıkla uygulanan düşük maliyetli yöntemlerdendir (Mohamad vd., 2015). Detoksifikasyon amaciyla kullanılan aktif kömür ile muamele uygulamasi ise, serbest yağ asitleri, nhekzan, pigmentler ve diğer inhibitör bileşenlerin uzaklaştırılmasını sağlayan etkili ve ekonomik bir yöntem olarak bilinmektedir. Aktif kömür ile muamele uygulamasının etkinliğinin $\mathrm{pH}$, sıcaklık, temas süresi ve hidrolizattaki aktif kömür oranı $(\mathrm{w} / \mathrm{v})$ gibi farklı proses parametrelerine bağlı olarak değiştiği belirtilmektedir. Düşük $\mathrm{pH}$ değerlerinde gerçekleştirilen uygulamalar hidrolizatlarda bulunan iyonlaşmamış yapıdaki fenolik maddelerin, yüksek $\mathrm{pH}$ değerleri ise organik bileşiklerin uzaklaştırılmasını sağlamaktadır. Hidrolizatların arıtılması işlemi, aktif kömürün hidrolizat ile temas süresinin arttırilmasından olumlu yönde etkilenmektedir. Ayrıca, inhibitör bileşenlerin aktif kömür tarafindan tutulmasinı hizlandırması nedeni ile, genellikle bu işlemin yüksek sıcaklıklarda gerçekleştirildiği bildirilmektedir (Ur Rehman vd., 2015). Hidrolizattaki aktif kömür oran1 (0.1-0.3 $\mathrm{g} / \mathrm{g}$ ), uygulama süresi (10-70 dak) ve sıcaklığ 1 (30$\left.80^{\circ} \mathrm{C}\right)$ olmak üzere farklı parametrelerin misır koçanı hidrolizatının detoksifikasyonu üzerine etkisinin incelendiği bir çalışmada optimum değerler sırası ile $0.2 \mathrm{~g} / \mathrm{g}$, 40 dakika ve $80^{\circ} \mathrm{C}$ olarak rapor edilmiştir (Wang vd., 2013a). Mısır koçanı hidrolizatı ile ilgili yapılan diğer bir çalışmada ise, $\mathrm{pH}$ ayarlama ve aktif kömür uygulamaları birlikte kullanılmış ve işlemler sonucunda furfural bileşeninin tamamının, fenolik maddelerin ve asetik asitin ise oldukça büyük bir çoğunluğunun ortamdan uzaklaştırılabildiği bildirilmiştir (Misra vd., 2013). Zeytin ağac1 budama artıklar1 kullanılarak hazırlanan hidrolizat, belirlenen optimum koşullar altında aktif kömür uygulamasına tabi tutulduğunda asetik asitin $\% 46$ 's1, fenolik maddelerin \%81'i, furfural ve HMF'nin ise tamamına yakınının hidrolizattan uzaklaştırıldığı belirtilmiştir. Aynı çalışmada, $\mathrm{pH}$ ayarlama ve organik çözücü ekstraksiyonu yöntemleri uygulandığında, hidrolizatın içerdiği inhibitör derişimlerinin daha yüksek olduğu bildirilmiş ve bu sebeple elde edilen hidrolizatın arıtılmasında aktif kömür uygulaması önerilmiştir (Mateo vd., 2013). Hemiselülozik hidrolizatların inhibitörlerden arındırılması işlemlerinde iyon değiştirici reçinelerden de yararlanıldığı, özellikle anyon değiştirici reçineler kullanıldığında hidrolizatlardaki furfural, asetik asit, HMF ve fenolik maddelerin, ayrıca aldehit ve alifatik asitlerin önemli ölçüde uzaklaştırıldığ belirtilmiştir (Ur Rehman vd., 2015).

Hidrolizatların arıtılmasında, mikroorganizmalar veya enzimlerin kullanıldığı biyolojik yöntemlerden yararlanılan çeşitli çalışmalar da bulunmaktadır. Hidrolizattaki inhibitör bileşenlerin bazı mikroorganizmalar tarafindan metabolize edilmesi ile gerçekleştirilen biyolojik detoksifikasyon yöntemlerinin, enerji gereksinimlerinin daha düşük olması, istenmeyen bazı reaksiyon ürünlerinin açığa çıkmaması ve hidrolizatta hacim kayb1 gerçekleşmemesi gibi avantajlara sahip olduğu belirtilmektedir. Misır sap1 hidrolizatının fermantasyon ortamı olarak değerlendirildiği bir çalışmada, hidrolizattaki furfural, HMF ve diğer inhibitörlerin ortamdan etkili bir şekilde uzaklaştırlmasinda Coniochaeta ligniaria suşunun kullanıldığı bildirilmiştir. Hidrolizatların enzimler kullanılarak arındırıl-masında ise genellikle lakkaz ve peroksidaz enzimlerinden yararlanilmaktadır. Ayrıca, son yıllarda hidrolizatların detoksifikasyonu ile ilgili olarak gerçekleştirilen bazı çalısmalarda, nanofiltrasyon, vakum membran distilasyonu ve elektrokimyasal yöntemlerin kullanıldığı bildirilmektedir (Rao vd., 2016). 


\section{SONUÇ}

Kimyasal yöntemlerle yapılan ksilitol üretimi ile karşılaştırıldığında, fermantasyon ortamı olarak hemiselülozik hidrolizatların kullanıldığ1 mikrobiyel ksilitol üretimi çalışmalarının genel olarak daha az maliyet gerektirdikleri belirtilmektedir. Ayrıca, katma değeri yüksek bir ürün olan ksilitolün üretiminde substrat kaynağ1 olarak, doğada çok fazla miktarda bulunan lignoselülozik artıklardan yararlanılması sayesinde, bu artıkların neden olduğu çevre kirliliğinin azaltılmasına katkı sağlanmaktadır. Ancak, mikroorganizmaların ksilitol üretebildikleri uygun koşulların belirlenmesi ve sağlanması amacıyla, fermantasyon ortamı hazırlık aşamalarının farklı bileşimlerdeki lignoselülozik artıklar için ayrı ayrı optimize edilmesi gerekmektedir. Mikrobiyel ksilitol üretiminin, kimyasal üretimin yerini tamamen alabilmesi için; inhibitörlere dirençli yeni suşların geliştirilmesine veya kolay uygulanabilen detoksifikasyon yöntemlerinin kullanımına yönelik daha fazla çalışmaya ihtiyaç duyulduğu belirtilmektedir.

\section{KAYNAKLAR}

Albuquerque, T.L.d., Silva, I.J.d., Macedo, G.R.d., Rocha, M.V.P. (2014). Biotechnological production of xylitol from lignocellulosic wastes: a review. Process Biochem, 49(11): 1779-1789.

Albuquerque, T.L.d., Gomes, S.D.L., Marques, J.E., Silva, I.J.d., Rocha, M.V.P. (2015). Xylitol production from cashew apple bagasse by Kluyveromyces marxianus CCA510. Catal Today, 255: 33-40.

Arrizon, J., Mateos, J.C., Sandoval, G., Aguilar, B., Solis, J., Aguilar, M.G. (2012). Bioethanol and xylitol production from different lignocellulosic hydrolysates by sequential fermentation. J Food Process Eng, 35(3): 437-454.

Camargo, D., Sene, L., Variz, D.I.L.S., Felipe, M.G.A. (2015). Xylitol bioproduction in hemicellulosic hydrolysate obtained from sorghum forage biomass. Appl Biochem Biotechnol, 175(8): 3628-3642.

Castañón Rodríguez, J.F., Portilla Arias, J.A., Aguilar Uscanga, B.R., Aguilar Uscanga MG (2015). Effects of oxygen and nutrients on xylitol and ethanol production in sugarcane bagasse hydrolyzates. Food Sci Biotechnol, 24(4): 1381-1389.

Chandel, A.K., Silva, S.S.d., Singh, O.V. (2013). Detoxification of lignocellulosic hydrolysates: biochemical and metabolic engineering toward white biotechnology. BioEnerg Res, 6(1): 388-401.

Chen, H., Liu, J., Chang, X., Chen, D., Xue, Y., Liu, P., Lin, H., Han, S. (2017). A review on the pretreatment of lignocellulose for high-value chemicals. Fuel Process Technol, 160: 196-206.

Cheng, K.K., Ling, H.Z., Zhang, J.A., Ping, W.X., Huang, W., Ge, J.P., Xu, J.M. (2010). Strain isolation and study on process parameters for xylose-to-xylitol bioconversion. Biotechnol Biotec Eq, 24(1): 1606-1611.

Dalli, S.S., Patel, M., Rakshit, S.K. (2017). Development of evaluation of poplar hemicellulosic prehydrolysate upstream processes for the enhanced fermentative production of xylitol. Biomass Bioenerg, 105: 402-410.

Dasgupta, D., Bandhu, S., Adhikari, D.K., Ghosh, D. (2017). Challenges and prospects of xylitol production with whole cell bio-catalysis: a review. Microbiol Res, 197: 9-21.

Deng, L., Wang, Y., Zhang, Y., Ma, R. (2007). The enhancement of ammonia pretreatment on the fermentation of rice straw hydrolysate to xylitol. $J$ Food Biochem, 31(2): 195-205.

Eryaşar, K., Karasu Yalçın, S. (2016). Evaluation of some lignocellulosic byproducts of food industry for microbial xylitol production by Candida tropicalis. 3 Biotech, 6: 202.

Grembecka, M. (2015). Sugar alcohols-their role in modern world of sweeteners: a review. Eur Food Res Technol, 241(1): 1-14.

Guamán Burneo, M.C., Dussán, K.J., Cadete, R.M., Cheab, M.A.M., Portero, P., Carvajal Barriga, E.J., Silva, S.S., Rosa, C.A. (2015). Xylitol production by yeasts isolated from rotting wood in the Gálapagos Islands, Ecuador, and description of Cyberlindnera galapagoensis f.a., sp. nov. A van Leeun J Microb, 108(4): 919-931.

Guo, X., Zhang, R., Li, Z., Dai, D., Li, C., Zhou, $X$. (2013). A novel pathway construction in 
Candida tropicalis for direct xylitol conversion from corncob xylan. Bioresource Tecbnol, 128: 547-552.

Gupta, R., Gautam, S., Shukla, R., Kuhad, R.C. (2017). Study of charcoal detoxification of acid hydrolysate from corncob and its fermentation to xylitol. J Environ Chem Eng, 5(5): 4573-4582.

Hernández Pérez, A.F., Costa, I.A.L., Silva, D.D.V., Dussán, K.J., Villela, T.R., Canettieri, E.V., Carvalho, J.A., Neto, T.G.S., Felipe, M.G.A. (2016). Biochemical conversion of sugarcane straw hemicellulosic hydrolyzate supplemented with co-substrates for xylitol production. Bioresource Technol, 200: 1085-1088.

Jain, H., Mulay, S. (2014). A review on different modes and methods for yielding a pentose sugar: xylitol. Int J Food Sci Nutr, 65(2): 135-143.

Jeon, Y.J., Shin, H.S., Rogers, P.L. (2011). Xylitol production from a mutant strain of Candida tropicalis. Lett Appl Microbiol, 53(1): 106-113.

Jönsson, L.J., Martín, C. (2016). Pretreatment of lignocellulose: formation of inhibitory byproducts and strategies for minimizing their effects. Bioresource Technol, 199: 103-112.

Kamat, S., Gaikwad, S., Ravi Kumar, A., Gade, W.N. (2013). Xylitol production by Cyberlindnera (Williopsis) saturnus, a tropical mangrove yeast from xylose and corn cob hydrolysate. J Appl Microbiol, 115(6): 1357-1367.

Kim, S.H., Yun, J.Y., Kim, S.G., Seo, J.H., Park, J.B. (2010). Production of xylitol from D-xylose and glucose with recombinant Corynebacterium glutamicum. Ensyme Microb Technol, 46(5): 366-371.

Li, M., Meng, X., Diao, E., Du, F. (2012). Xylitol production by Candida tropicalis from corn cob hemicellulose hydrolysate in a two-stage fedbatch fermentation process. $J$ Chem Technol Biot, 87(3): 387-392.

Li, Z., Qu, H., Li, C., Zhou, X. (2013). Direct and efficient xylitol production from xylan by Saccharomyces cerevisiae through transcriptional level and fermentation processing optimizations. Bioresource Technol, 149: 413-419.

Lourenço, M.V.M., Dini Andreote, F., Aguilar Vildoso, C.I., Basso, L.C. (2014).
Biotechnological potential of Candida spp. for the bioconversion of D-xylose to xylitol. Afr $J$ Microbiol Res, 8(20): 2030-2036.

Mateo, S., Roberto, I.C., Sánchez, S., Moya, A.J. (2013). Detoxification of hemicellulosic hydrolyzate from olive tree pruning residue. Ind Crop Prod, 49: 196-203.

Mateo, S., Puentes, J.G., Roberto, I.C., Sánchez, S., Moya, A.J. (2014). Optimization of acid hydrolysis of olive tree pruning residue. Fermentation with Candida guilliermondii. Biomass Bioenerg, 69: 39-46.

Misra, S., Raghuwanshi, S., Saxena, R.K. (2013). Evaluation of corncob hemicellulosic hydrolysate for xylitol production by adapted strain of Candida tropicalis. Carbobyd Polym, 92(2): 1596-1601.

Miura, M., Watanabe, I., Shimotori, Y., Aoyama, M., Kojima, Y., Kato, Y. (2013). Microbial conversion of bamboo hemicellulose hydrolyzate to xylitol. Wood Sci Technol, 47: 515-522.

Miura, M., Shimotori, Y., Nakatani, H., Harada, A., Aoyama, M. (2015). Bioconversion of birch wood hemicellulose hydrolyzate to xylitol. Appl Biochem Biotech, 176: 947-955.

Mohamad, N.L., Mustapa Kamal, S.M., Mokhtar, M.N. (2015). Xylitol biological production: a review of recent studies. Food Rev Int, 31(1): 74-89.

Mohamad, N.L., Mustapa Kamal, S.M., Mokhtar, M.N., Husain S.A., Abdullah, N. (2016). Dynamic mathematical modelling of reaction kinetics for xylitol fermentation using Candida tropicalis. Biochem Eng J, 111: 10-17.

Mussatto, S.I., Roberto, I.C. (2008). Establishment of the optimum initial xylose concentration and nutritional supplementation of brewer's spent grain hydrolysate for xylitol production by Candida guilliermondii. Process Biochem, 43(5): 540-546.

Pal, S., Choudhary, V., Kumar, A., Biswas, D., Mondal, A.K., Sahoo, D.K. (2013). Studies on xylitol production by metabolic pathway engineered Debaryomyces hansenii. Bioresource Technol, 147: 449-455. 
Pérez Bibbins, B., Torrado Agrasar, A., Pérez Rodríguez, N., Aguilar Uscanga, M.G., Domínguez, J.M. (2015). Evaluation of the liquid, solid and total fractions of beer, cider and wine lees as economic nutrient for xylitol production. $J$ Chem Technol Biot, 90(6): 1027-1039.

Ping, Y., Ling, H.Z., Song, G., Ge, J.P. (2013). Xylitol production from non-detoxified corncob hemicellulose acid hydrolysate by Candida tropicalis. Biochem Eng J, 75: 86-91.

Rafiqul, I.S.M., Mimi Sakinah, A.M. (2013). Processes for the production of xylitol- a review. Food Rev Int, 29(2): 127-156.

Rafiqul, I.S.M., Mimi Sakinah, A.M., Zularisam, A.W. (2015). Inhibition by toxic compounds in the hemicellulosic hydrolysates on the activity of xylose reductase from Candida tropicalis. Biotechnol Lett, 37: 191-196.

Rao, L.V., Goli, J.K., Gentela, J., Koti, S. (2016). Bioconversion of lignocellulosic biomass to xylitol: an overview. Bioresource Technol, 213:299310.

Rambo, M.K.D., Bevilaqua, D.B., Brenner, C.G.B., Martins, A.F., Mario, D.N., Alves, S.H., Mallmann, C.A. (2013). Xylitol from rice husks by acid hydrolysis and Candida yeast fermentation. Quim Nova, 36(5): 634-639.

Rivas, B., Torrado, A., Rivas, S., Moldes, A.B., Domínguez, J.M. (2007). Simultaneous lactic acid and xylitol production from vine trimming wastes. J Sci Food Agr, 87(8): 1603-1612.

Rocha, M.V.P., Rodrigues, T.H.S., Albuquerque, T.L.d., Gonçalves, L.R.B., Macedo, G.R.d. (2014). Evaluation of dilute acid pretreatment on cashew apple bagasse for ethanol and xylitol production. Chem EngJ, 243: 234-243.

Salgado, J.M., Rodríguez, N., Cortés, S., Domínguez, J.M. (2012). Effect of nutrient supplementation of crude or detoxified concentrated distilled grape marc hemicellulosic hydrolysates on the xylitol production by Debaryomyces hansenii. Prep Biochem Biotech, 42(1): 114.

Silva, D.D.V., Arruda, P.V.d., Vicente, F.M.C.F., Sene, L., Silva, S.S.d., Felipe, M.G.A. (2015).
Evaluation of fermentative potential of Kluyveromyces marxianus ATCC 36907 in cellulosic and hemicellulosic sugarcane bagasse hydrolysates on xylitol and ethanol production. Ann Microbiol, 65: 687-694.

Su, B., Wu, M., Zhang, Z., Lin, J., Yang, L. (2015). Efficient production of xylitol from hemicellulosic hydrolysate using engineered Escherichia coli. Metab Eng, 31: 112-122.

Ur Rehman, S., Mushtaq, Z., Zahoor, T., Jamil, A., Murtaza, M.A. (2015). Xylitol; a review on bioproduction, application, health benefits and related safety issues. Crit Rev Food Sci, 55(11): 1514-1528.

Vallejos, M.E., Chade, M., Mereles, E.B., Bengoechea, D.I., Brizuela, J.G., Felissia, F.E., Area, M.C. (2016). Strategies of detoxification and fermentation for biotechnological production of xylitol from sugarcane bagasse. Ind Crop Prod, 91: 161-169.

Villarreal, M.L.M., Prata, A.M.R., Felipe, M.G.A., Almeida e Silva, J.B. (2006). Detoxification procedures of eucalyptus hemicellulose hyrolysate for xylitol production by Candida guilliermondii. Ensyme Microb Tech, 40(1): 17-24.

Wang, L., Fan, X., Tang, P., Yuan, Q. (2013a). Xylitol fermentation using hemicellulose hydrolysate prepared by acid pre-impregnated steam explosion of corncob. J Chem Technol Biot, 88(11): 2067-2074.

Wang, L., Wu, D., Tang, P., Yuan, Q. (2013b). Effect of organic acids found in cottonseed hull hydrolysate on the xylitol fermentation by Candida tropicalis. Bioproc Biosyst Eng, 36(8): 1053-1061.

Wannawilai, S., Chisti, Y., Sirisansaneeyakul, S. (2017). A model of furfural-inhibited growth and xylitol production by Candida magnoliae TISTR 5663. Food Bioprod Process, 105: 129-140.

Winkelhausen, E., Kuzmanova, S. (1998). Microbial conversion of D-xylose to xylitol. $J$ Ferment Bioeng, 86(1): 1-14.

Zada, B., Chen, M., Chen, C., Yan, L., Xu, Q., Li, W., Guo, Q., Fu, Y. (2017). Recent advances in catalytic production of sugar alcohols and their applications. Sci China Chem, 60(7): 853-869. 
Zhang, J., Geng, A., Yao, C., Lu, Y., Li, Q. (2012a). Effects of lignin-derived phenolic compounds on xylitol production and key enzyme activities by a xylose utilizing yeast Candida athensensis SB18. Bioresource Technol, 121: 369-378.
Zhang, J., Geng, A., Yao, C., Lu, Y., Li, Q. (2012b). Xylitol production from D-xylose and horticultural waste hemicellulosic hydrolysate by a new isolate of Candida athensensis SB18. Bioresource Technol, 105: 134-141. 